\title{
Short communication Oestrogen is bad for patients with breast cancer?
}

\author{
V Craig Jordan ${ }^{1}$, Eric A Ariazi ${ }^{1}$, Joan S Lewis-Wambi ${ }^{1}$, Ramona R Swaby ${ }^{1}$, Heather E Cunliffe ${ }^{2}$, \\ Anna T Riege ${ }^{3}$ and Anton Wellstein ${ }^{3}$
}

\author{
${ }^{1}$ Fox Chase Cancer Center, Philadelphia, Pennsylvania 19111, USA \\ ${ }^{2}$ Translational Genomics Research Institute, Phoenix, Arizona 85004, USA \\ ${ }^{3}$ Vincent T Lombardi Cancer Center, Georgetown University, Washington, District of Columbia 20057, USA
}

Corresponding author: V Craig Jordan, v.craig.jordan@fccc.edu

Published: 20 December 2007

This article is online at http://breast-cancer-research.com/content/9/S2/S22 (c) 2007 BioMed Central Ltd

Breast cancer is a hormone-dependent disease, and a proportion of patients with oestrogen receptors (ERs) will respond to ovarian ablation [1-3]. For this reason, oestrogen is considered bad for patients with breast cancer. This short communication presents our evolving understanding of oestrogen's role as a survival signal in breast cancer and new emerging knowledge of the apoptotic actions of oestrogen [4].

Synthetic oestrogens based either on the structure of triphenylethylene or the very potent but shorter acting diethylstilboestrol $[5,6]$ were described more than 60 years ago. This proved to be a cheap source of new medicines. High-dose synthetic oestrogen administration was found to be effective in the treatment of breast and prostate cancer [7], but low-dose synthetic oestrogens never really became accepted as hormone replacement therapy in postmenopausal women. Indeed, diethylstilboestrol subsequently achieved notoriety as an oestrogen supplement to prevent recurrent abortion. Children of treated mothers had a high incidence of clear cell carcinoma of the vagina $[8,9]$. In contrast, the synthetic oestrogens based on triphenylethylenes were subsequently to undergo a metamorphosis and be transformed into anti-oestrogens used for the treatment of breast cancer [10].

Based on the link identified between oestrogen and the development and growth of some breast cancers, the current strategy for the treatment and prevention of ER-positive breast cancer is the application of long-term antihormonal therapy [11]. The use of long-term tamoxifen therapy [12] has had a profound effect on survival, but in addition the wide distribution of tamoxifen has resulted in a declining death rate from breast cancer over the past few years. Currently, the aromatase inhibitors [13-15] are proving to represent a modest improvement over tamoxifen therapy, especially for the postmenopausal woman with concerns about endometrial cancer and blood clots. However, tamoxifen remains the
Breast Cancer Research 2007, 9(Suppl 2):S22 (doi:10.1186/bcr1820)

treatment of choice for the premenopausal woman with ERpositive breast cancer.

The past 30 years have seen dramatic advances in the practical prospects for the chemoprevention of breast cancer. Studies in the laboratory with tamoxifen $[16,17]$ and raloxifene $[18,19]$ have now translated into clinical practice for either chemoprevention of breast cancer in high-risk women with tamoxifen $[20,21]$ or treatment of osteoporosis with prevention of breast cancer with raloxifene $[22,23]$. However, widespread use of long-term antihormonal therapies for the treatment and prevention of breast cancer creates consequences for the tumour in the form of antihormonal drug resistance. Nevertheless, laboratory study of antihormonal drug resistance has revealed an unanticipated vulnerability of breast cancer cells.

It has been known for about 20 years that long-term oestrogen treatment of athymic mice inoculated with the ERpositive breast cancer cell line MCF7 will result in transplantable ER-positive tumours [24]. Tamoxifen will initially prevent tumour growth, but long-term tamoxifen therapy causes tumours to become drug-resistant, which is expressed as tamoxifen-stimulated growth [25]. This model system replicates the clinical situation for the treatment of advanced breast cancer, and second-line therapies in the clinic are usually an aromatase inhibitor or the pure anti-oestrogen fulvestrant [26,27]. However, the process of developing tamoxifen-stimulated tumour growth in the laboratory, which takes 1 to 2 years, does not replicate adjuvant therapy with tamoxifen, which has a duration of 5 years. To address this issue, tamoxifen-stimulated tumours were serially transplanted into successive generations of athymic mice and a novel form of drug resistance was recognized. Tamoxifen and other selective ER modulators (SERMs) such as raloxifene stimulate tumour growth [28], but remarkably oestrogen now does not support tumour growth but causes rapid tumour regression $[29,30]$. 


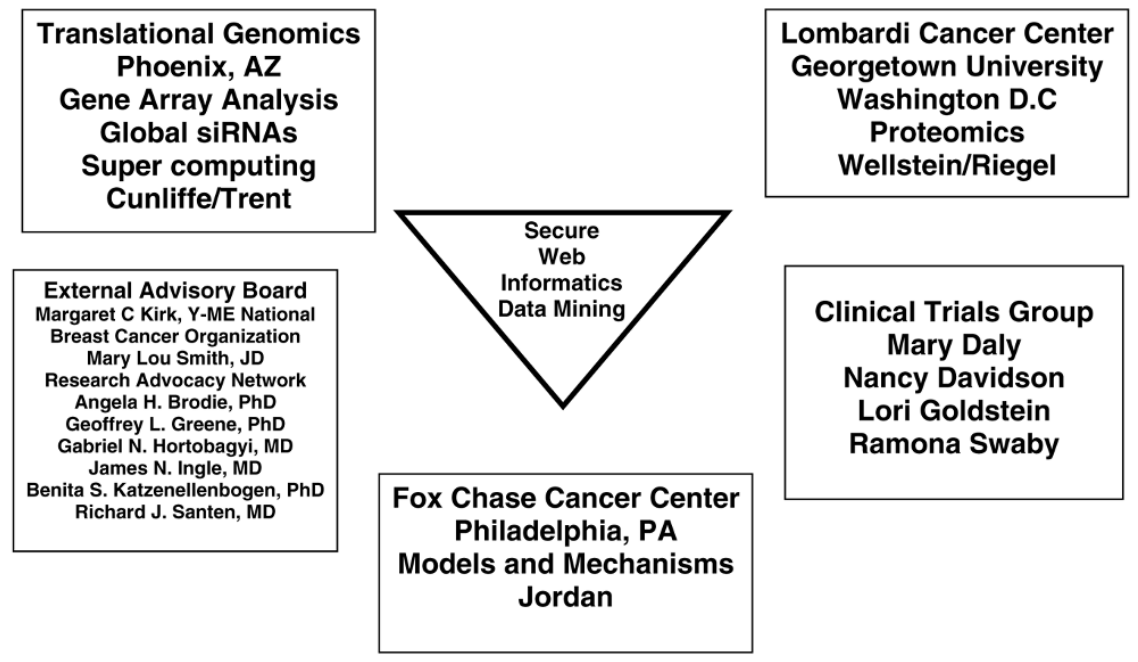

Organization of Department of Defense Center of Excellence Grant. Shown is the organization of our Department of Defense Center of Excellence Grant entitled 'A new therapeutic paradigm for breast cancer exploiting low-dose oestrogen-induced apoptosis'. The model systems to study the survival and apoptosis induced with oestrogen are being used in time course experiments at the Fox Chase Cancer Center. The materials are distributed to Translational Genomics for genomic analysis using comparative genomic hybridization, small interfering (si)RNA analysis or Agilent gene array analysis, and the Vincent T Lombardi Cancer Center is involved in conducting proteomics analysis. All results are uploaded into a shared secure web for data processing and target identification by our informatics and biostatistical group. Each laboratory is able to validate emerging pathways and study individual genes of interest. Our programme is integrated with a clinical trials programme that provides patient samples for validation of apoptotic or survival pathways. We are grateful to our external advisory board of patient advocates and professional colleagues for their continuing advice and support.

This action of oestrogen after 5 or more years of tamoxifen therapy demonstrates that there is an evolution of drug resistance in breast cancer cells. This was recently classified [31]. The early phases of drug resistance with tamoxifen are referred to as phase I resistance. This is indicated by a tumour growing with either tamoxifen or oestrogen treatment. In contrast, phase II resistant tumours grow only with tamoxifen, and oestrogen kills tumour cells. Similar studies are now being conducted using long-term oestrogen deprivation to replicate what will occur with the aromatase inhibitors [32].

Early studies growing MCF7 breast cancer cells in oestrogen-free media identified increased intracellular ER levels and spontaneous cell growth [33,34]. Several oestrogen-independent clones were isolated for study $[35,36]$ and the idea was proposed that MCF7 cells are hypersensitized to grow in extremely low levels of oestrogen (below the level that can be detected or further reduced) [37]. However, Song and coworkers [38] observed that increasing concentrations of oestradiol could increase apoptosis in oestrogen-deprived cells by increasing the concentration of Fas ligand that activates death receptor pathways. Thus, the original observations that phase II tamoxifen resistant tumours could be treated with physiological oestrogen $[29,30]$ were extended to aromatase inhibitor resistant cells. However, in contrast to the study conducted by Song and coworkers [38], phase II tamoxifen resistant tumours respond to increasing oestrogen treatment by increasing the Fas receptor, and decreasing HER2/neu and nuclear factor- $\kappa$, which is associated with tumour regression [39]. Furthermore, MCF7 cells kept for many years under oestrogen-depleted conditions using medium containing stripped foetal bovine serum produce rapid apoptosis via an intrinsic mechanism directed at the mitochondrion [40,41]. However, both Lewis and coworkers [41] and Song and Santen [42] found that apoptosis is modulated through bcl-2 or bcl-2XL.

It is also perhaps important to note that the new knowledge about oestrogen action emerged through re-examination of existing cell lines. In early reports on the effects of oestrogen withdrawal, no oestrogen-induced apoptosis was noted $[35,36]$, but by altering culture conditions or extending the period of oestrogen exposure, apoptosis occurs [40,41,43]. Overall, the phenomenon observed with long term oestrogen withdrawal is similar to the phase II resistance of the model described for SERMs [32].

Lonning and coworkers [44] addressed the hypothesis that patients with ER-positive breast cancers who have been treated exhaustively with antihormonal therapy could potentially respond to high-dose oestrogen therapy. Thirty- 
Figure 2

\section{TREATMENT PLAN FOR THIRD LINE THERAPY}

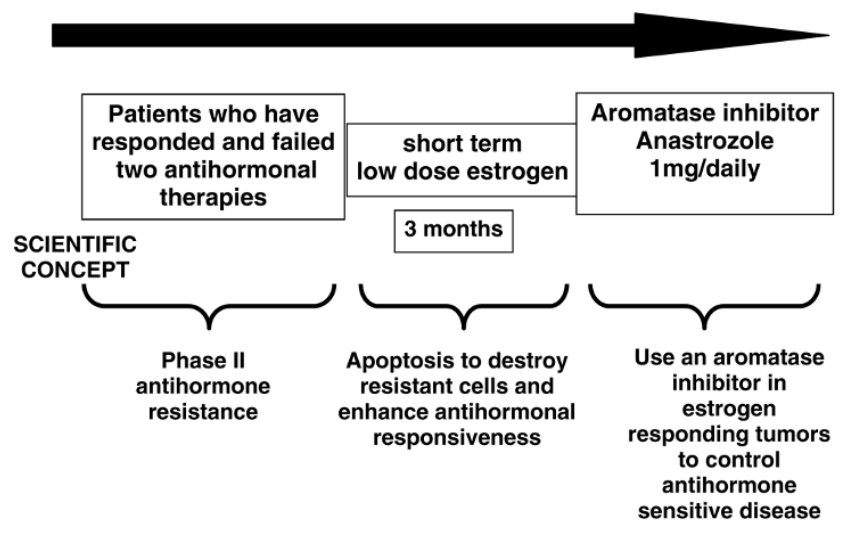

Anticipated treatment plan for third-line endocrine therapy. Patients must have responded and failed two successive antihormonal therapies to be eligible for a course of low-dose oestradiol therapy for 3 months. The anticipated response rate is 30\% [44] and responding patients will be treated with anastrozole until relapse. Validation of the treatment plan via the Center of Excellence Grant (Figure 1) will establish a platform to enhance response rates with apoptotic oestrogen by integrating known inhibitors of tumour survival pathways into the 3-month low-dose oestrogen debulking treatment plan. The overall goal is to increase response rates and maintain patients for longer on antihormonal strategies before chemotherapy is required.

two patients with advanced breast cancer previously exposed to between two and ten (median four) endocrine treatments were treated with diethylstilboestrol $5 \mathrm{mg}$ three times daily. Therapy was well tolerated but four patients terminated treatment within 2 weeks of starting and another two stopped treatment before progression. One of these patients had stable disease for 15 weeks and one a partial response for 39 weeks. Of the remainder, four patients obtained a complete response and six patients a partial response. Two patients had stable disease for 6 months and one for more than 1 year. Overall, these extremely encouraging preliminary studies with high-dose oestrogen therapy are complemented by anecdotal reports of the effectiveness of low-dose oestrogen treatment for those women with endocrine refractory breast cancer after exhaustive antihormonal therapy (Ingle J, Dixon M, personal communication). As a result, several clinical studies are currently underway (Ellis $M$, Santen R, personal communications).

Based on preclinical laboratory modelling, we have translated the new biology of oestrogen action into a Department of Defense Center of Excellence grant with laboratory and clinical collaborators illustrated in Figure 1. Our goal is to define the pathways for oestrogen-induced survival and apoptosis in endocrine responsive breast and endometrial cancer, and to use the emerging database to guide the interpretation and development of a series of clinical trials.
The ultimate goal of our clinical trial design is illustrated in Figure 2 and currently consists of two separate but interconnected therapeutic oestrogen studies, designed to determine the lowest dose of a 12-week course of oestrogen that causes a positive therapeutic effect.

In summary, the development and extensive clinical application of long-term antihormonal therapy [11] has had consequences for the patient with the development of antihormonal drug resistance in some breast cancers [31]. However, with the development of drug resistance to exhaustive antihormonal therapy, a vulnerability of the cancer has been exposed. The recognition of the new biology of oestrogen action that causes apoptosis in sensitive breast tumours now opens an unanticipated door of opportunity to exploit the findings to aid patients. Although the actual clinical responses may not be profound in unselected patient populations or in populations whose tumours do not have the correct (stage II) form of breast cancer drug resistance, our ability to decipher apoptotic mechanisms from laboratory models, and eventually to target patients appropriately, may have profound and positive effects for some patients. The translational knowledge gained over the coming few years may again provide unanticipated opportunities to exploit the discovery of 'apoptotic triggers' for other forms of cancer.

It is perhaps pertinent to restate that for 70 years there has been an 'ebb and flow' relationship for the role of oestrogen in breast tumour homeostasis. We have illustrated in this article many of the changing fashions that have occurred in the perception of oestrogen as either hero or villain with repect to women's health. The effects of modulating the ER system in the breast, at one time or another, have been dismissed because the effects are small or believed to be of no major consequence. Nevertheless, the number of events becomes accumulative. By way of example, it is important to recall that initial use of tamoxifen, a failed contraceptive, to treat unselected populations yielded only modest responses for some patients with metastatic breast cancer [45]. Years later, after deciphering the target populations and translating the appropriate treatment strategies from the laboratory to the clinic, the drug became the 'gold standard' for endocrine therapy [45] and was credited with improving the survival of hundreds of thousands of women [12]. The challenge for the future is to exploit the profound apoptotic action of oestradiol as a lead to develop innovative new therapies for cancer.

\section{Acknowledgements}

Dr Jordan is supported by the Department of Defense Breast Program under award number BC050277 Center of Excellence (views and opinions of, and endorsements by the author(s) do not reflect those of the US Army or the Department of Defense), R01 GM067156, FCCC Core Grant NIH P30 CA006927 and the Weg Fund of Fox Chase Cancer Center.

This article has been published as part of Breast Cancer Research Volume 9 Supplement 2, 2007: Controversies in Breast Cancer. The full contents of the supplement are available online at http://breastcancer-research.com/supplements/9/S2. 


\section{References}

1. Beatson CT: On treatment of inoperable cases of carcinoma of the mamma: suggestions for a new method of treatment with illustrative cases. Lancet 1896, 2:162-165.

2. Boyd S: On oophorectomy in cancer of the breast. BMJ 1900, ii:1161-1167.

3. McGuire WL, Carbone PP, Sears ME, Escher GC: Estrogen receptors in human breast cancer: an overview. In Estrogen Receptor in Human Breast Cancer. Edited by McGuire WL, Carbone PP, Volmer EP. New York, NY: Raven Press; 1975:1-7.

4. Lewis JS, Cheng D, Jordan VC: Targeting oestrogen to kill the cancer but not the patient. Br J Cancer 2004, 90:822-832.

5. Dodds EC, Goldberg L, Lawson W, Robinson R: Oestrogenic activity of certain synthetic compounds. Nature 1938, 141: 247-248.

6. Robson JM, Schonberg A, Fahim HA: Duration of action of natural and synthetic estrogens. Nature 1938, 142:292-293.

7. Haddow A, Watkinson JM, Paterson E: Influence of synthetic oestrogens upon advanced malignant disease. BMJ 1944, 2: 393-398.

8. Greenwald P, Barlow JJ, Nasca PC, Burnett WS: Vaginal cancer after maternal treatment with synthetic estrogens. $N$ Engl J Med 1971, 285:390-392.

9. Herbst AL, Ulfelder H, Poskanzer DC: Adenocarcinoma of the vagina. Association of maternal stilbestrol therapy with tumor appearance in young women. N Engl J Med 1971, 284:878-881.

10. Lerner LJ, Jordan VC: The development of antiestrogens for the treatment of breast cancer: Eighth Cain Memorial Award Lecture. Cancer Res 1990, 50:4177-4189.

11. Jordan VC, Brodie AMH: Development and evolution of therapies targeted to the estrogen receptor for the treatment and prevention of breast cancer. Steroids 2007, 72:7-25.

12. Early Breast Cancer Trialists' Collaborative Group (EBCTCG): Effects of chemotherapy and hormonal therapy for early breast cancer on recurrence and 15-year survival: an overview of the randomised trials. Lancet 2005, 365:1687-1717.

13. Howell A, Cuzick J, Baum M, Buzdar A, Dowsett M, Forbes JF, Hoctin-Boes G, Houghton J, Locker GY, Tobias JS; ATAC Trialists' Group: Results of the ATAC (Arimidex, Tamoxifen, Alone or in Combination) trial after completion of 5 years' adjuvant treatment for breast cancer. Lancet 2005, 365:60-62.

14. Breast International Group (BIG) 1-98 Collaborative Group; Thürlimann B, Keshaviah A, Coates AS, Mouridsen H, Mauriac L, Forbes JF, Paridaens R, Castiglione-Gertsch M, Gelber RD, Rabaglio M, et ali: A comparison of letrozole and tamoxifen in postmenopausal women with early breast cancer. $N$ Engl J Med 2005, 353:2747-2757.

15. Coates AS, Keshaviah A, Thürlimann B, Mouridsen H, Mauriac L, Forbes JF, Paridaens R, Castiglione-Gertsch M, Gelber RD, Colleoni M, et al.: Five years of letrozole compared with tamoxifen as initial adjuvant therapy for postmenopausal women with endocrine-responsive early breast cancer: update of study BIG 1-98. J Clin Oncol 2007, 25:486-492.

16. Jordan VC: Effect of tamoxifen (ICl 46,474) on initiation and growth of DMBA-induced rat mammary carcinoma. Eur J Cancer 1976, 12:419-424.

17. Jordan VC, Allen KE: Evaluation of the antitumour activity of the non-steroidal antioestrogen monohydroxytamoxifen in the DMBA-induced rat mammary carcinoma model. Eur J Cancer 1980, 16:239-251.

18. Jordan VC, Phelps E, Lindgren JU: Effects of anti-estrogens on bone in castrated and intact female rats. Breast Cancer Res Treat 1987, 10:31-35.

19. Gottardis MM, Jordan VC: Antitumor actions of keoxifene and tamoxifen in the $\mathrm{N}$-nitrosomethylurea- induced rat mammary carcinoma model. Cancer Res 1987, 47:4020-4024.

20. Fisher B, Costantino JP, Wickerham DL, Redmond CK, Kavanah M, Cronin WM, Vogel V, Robidoux A, Dimitrov N, Atkins J, et al.: Tamoxifen for prevention of breast cancer: report of the National Surgical Adjuvant Breast and Bowel Project P-1 Study. J Nat/ Cancer Inst 1998, 90:1371-1388.

21. Fisher $B$, Costantino JP, Wickerham DL, Cecchini RS, Cronin WM, Robidoux A, Bevers TB, Kavanah MT, Atkins JN, Margolese $\mathrm{RG}$, et al:: Tamoxifen for the prevention of breast cancer: current status of the National Surgical Adjuvant Breast and Bowel Project P-1 study. J Natl Cancer Inst 2005, 97:16521662.
22. Cummings SR, Eckert S, Krueger KA, Grady D, Powles TJ, Cauley JA, Norton L, Nickelsen T, Bjarnason NH, Morrow M, et al.: The effect of raloxifene on risk of breast cancer in postmenopausal women: results from the MORE randomized trial. Multiple Outcomes of Raloxifene Evaluation. JAMA 1999, 281:2189-2197.

23. Vogel VG, Costantino JP, Wickerham DL, Cronin WM, Cecchini RS, Atkins JN, Bevers TB, Fehrenbacher L, Pajon ER Jr, Wade JL III, et al.; National Surgical Adjuvant Breast and Bowel Project (NSABP): The Study of Tamoxifen and Raloxifene (STAR): report of the National Surgical Adjuvant Breast and Bowel Project P-2 Trial. JAMA 2006, 295:2727-2741.

24. Osborne CK, Hobbs K, Clark GM: Effect of estrogens and antiestrogens on growth of human breast cancer cells in athymic nude mice. Cancer Res 1985, 45:584-591.

25. Gottardis MM, Jordan VC: Development of tamoxifen-stimulated growth of MCF-7 tumors in athymic mice after long-term antiestrogen administration. Cancer Res 1988, 48:5183-5187.

26. Howell A, Robertson JFR, Quaresma Albano J, Aschermannova A, Mauriac L, Kleeberg UR, Vergot I, Erikstein B, Webster A, Morris

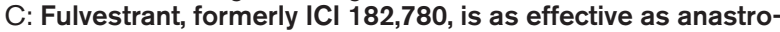
zole in postmenopausal women with advanced breast cancer progressing after prior endocrine treatment. J Clin Oncol 2002, 20:3396-3403.

27. Osborne CK, Pippen J, Jones SE, Parker LM, Ellis M, Come S, Gertler SZ, May JT, Burton G, Dimery I, et al.: Double-blind, randomized trial comparing the efficacy and tolerability of fulvestrant versus anastrozole in postmenopausal women with advanced breast cancer progressing on prior endocrine therapy: results of a North American trial. J Clin Oncol 2002, 20:3386-3395.

28. O'Regan RM, Gajdos C, Dardes RC, De Los Reyes A, Park W, Rademaker AW, Jordan VC: Effects of raloxifene after tamoxifen on breast and endometrial tumor growth in athymic mice. $J$ Natl Cancer Inst 2002, 94:274-283.

29. Yao K, Lee ES, Bentrem DJ, England G, Schafer Jl, O'Regan RM, Jordan VC: Antitumor action of physiological estradiol on tamoxifen-stimulated breast tumors grown in athymic mice. Clin Cancer Res 2000, 6:2028-2036.

30. Wolf DM, Jordan VC: A laboratory model to explain the survival advantage observed in patients taking adjuvent tamoxifen therapy. In Recent Results in Cancer Research, vol 127. Heidelberg, Germany: Springer-Verlag; 1993:23-33.

31. Jordan VC: Selective estrogen receptor modulation: concept and consequences in cancer. Cancer Cell 2004, 5:207-213.

32. Ariazi EA, Lewis-Wambi JS, Gill SD, Pyle JR, Ariazi JL, Kim HR, Sharma CG, Cordera F, Shupp HA, Li T, Jordan VC: Emerging principles for the development of resistance to antihormonal therapy: implications for the clinical utility of fulvestrant. $J$ Steroid Biochem Mol Biol 2006, 102:128-138.

33. Katzenellenbogen BS, Kendra KL, Norman MJ, Berthois Y: Proliferation, hormonal responsiveness, and estrogen receptor content of MCF-7 human breast cancer cells grown in the short-term and long-term absence of estrogens. Cancer Res 1987, 47:4355-4360.

34. Welshons WV, Jordan VC: Adaptation of estrogen-dependent MCF-7 cells to low estrogen (phenol red-free) culture. Eur J Cancer 1987, 232:1935-1939.

35. Jiang SY, Wolf DM, Yingling JM, Chang C, Jordan VC: An estrogen receptor positive MCF-7 clone that is resistant to antiestrogens and estradiol. Mol Cell Endocrinol 1992, 90:77-80.

36. Pink JJ, Jiang SY, Fritsch M, Jordan VC: An estrogen-independent MCF-7 breast cancer cell line which contains a novel 80 kilodalton estrogen receptor-related protein. Cancer Res 1995, 55:2583-2590.

37. Masamura S, Santner SJ, Heitjan DF, Santen RJ: Estrogen deprivation causes estradiol hypersensitivity in human breast cancer cells. J Clin Endocrinol Metab 1995, 80:2918-2925.

38. Song RX, Mor G, Naftolin F, McPherson RA, Song J, Zhang Z, Yue W, Wang J, Santen RJ: Effect of long-term estrogen deprivation on apoptotic responses of breast cancer cells to 17beta-estradiol. J Nat/ Cancer Inst 2001, 93:1714-1723.

39. Osipo C, Gajdos C, Liu H, Chen B, Jordan VC: Paradoxical action of fulvestrant on estradiol-induced regression of tamoxifen-stimulated breast cancer. J Natl Cancer Inst 2003, 95:1597-1607.

40. Lewis JS, Osipo C, Meeke K, Jordan VC: Estrogen induced apoptosis in breast cancer model resistant to long-term estro- 
gen withdrawal. J Steroid Biochem Mol Biol 2005, 94:131-141.

41. Lewis JS, Meeke K, Osipo C, Bell E, Kidawi N, Chandel NS, Jordan VC: Intrinsic mechanism of estradiol-induced apoptosis in breast cancer cells resistant to estrogen deprivation. $J$ Natl Cancer Inst 2005, 97:1746-1759.

42. Song RX, Santen RJ: Apoptotic action of estrogen. Apoptosis 2003, 8:55-60.

43. Jordan VC, Lewis-Wambi J, Kim H, Cunliffe H, Ariazi E, Sharma C Shupp HA, Swaby R: Exploiting the apoptotic actions of oestrogen to reverse antihormonal drug resistance in oestrogen receptor positive breast cancer patients. Breast 2007, 16(Suppl 2):105-113.

44. Lonning PE, Taylor PD, Anker G, Iddon J, Wie L, Jorgensen LM, Mella O, Howell A: High-dose estrogen treatment in postmenopausal breast cancer patients heavily exposed to endocrine therapy. Breast Cancer Res Treat 2001, 67:111-116.

45. Jordan VC: Tamoxifen: a most unlikely pioneering medicine. Nat Rev Drug Discov 2003, 2:205-213. 